\title{
DESAFIOS ATUAIS DA PSICOLOGIA NA INTERVENÇÃO SOCIAL
}

Ferrán Casas

Universitat de Girona, Espanha

RESUMO: Segundo o autor, os psicólogos que trabalham em intervenção psicossocial geralmente focalizam sua avaliação da mudança no nível microssocial, pessoal ou familiar. A Psicologia Social vêm destacando a importância dos contextos. Nas nossas sociedades atuais o macrocontexto possui alguma características únicas, inexistentes anteriormente: vivemos em tempos de rápidas mudanças. As novas mudanças, para os agentes que trabalham nos sistemas de bem-estar, repercutem especialmente naqueles envolvidos na nova dinâmica macrossocial. Desde essa perspectiva, pensamos na necessidade de mudança das representações sociais nos grupos sociais, de seus problemas sociais e da forma como cada um dos problemas é colocado. Indica-se a importância das dimensões não materiais da vida social nos processos de mudança social. São discutidas novas perspectivas e objetivos relativos ao conceito de qualidade de vida. Também se estuda a influência dos meios de comunicação nos processos de mudança social. E, finalmente, se apresenta um esquema que serve para refletir e discutir algumas mudanças relevantes na intervenção social.

Palavras-chave: Intervenção social; psicologia; problemas sociais; representações sociais; bem-estar; qualidade de vida; mídia; mudança social.

\section{CURRENT CHALLENGES IN PSYCHOLOGY OF SOCIAL INTERVENTION}

ABSTRACT: According the author, psychologists involved in social intervention programs are often focused in microsocial assessment and personal or family change. Social psychology has often underlined the importance of contexts. In our present societies the macrocontext has some unique characteristics, which never existed before: we live in an ever-quickening changing society. That raises a set of new challenges to practitioners of the welfare systems, particularly that of taking more into account the new macrosocial dynimics. From that perspective reflections about the need to change social representations of social groups, of their social problems and of the way to cope with such problems are proposed. The importance of non-material dimensions of social life in social change processes are pointed out. The new perspectives and goals involved with the quality of life concept are discussed. Media influence in the processes of social change are also considered. And finally an scheme to reflect and debate some outstanding challenges for social intervention are offered.

Key-words: Social intervention; psychology; social problems; social representations; well-being; quality of life; media; social change.

\section{O CONTEXTO MACROSSOCIAL E A COMPLEXIDADE}

Não podemos compreender nenhuma realidade social sem conhecer o contexto sócio-histórico em que se desenvolve. Um dos elementos mais fundamentais para analisar os desafios atuais da psicologia da intervenção social hoje é o fato de vivermos não só numa sociedade em transformação, mas em transformação acelerada. Isso nos diferencia de qualquer outra época histórica anterior. Cada vez mudam mais coisas, e cada vez mais rápido. Basta olhar, mesmo que seja por razões de proximidade e de implicação, o contexto europeu. Há duas décadas estamos submersos em impressionantes mudanças demográficas, políticas, sociais, culturais, tecno- lógicas... Tais mudanças penetram mais do que nunca nos nossos lares, e exercem influências extraordinárias em nossas vidas cotidianas, nas formas de nos relacionarmos, e em nossa maneira de pensar e de agir.

A complexidade das dinâmicas sociais dificulta tentativas de previsão. Hoje, porém, basta pensar numa das grandes coordenadas das mudanças sociais, como, p. ex., a tecnológica, e se chega a uma conclusão óbvia: A maior parte das previsões que fazemos sobre como será nossa vida em 20 anos são absolutamente incertas. Há 35 anos erramos as previsões que fizemos sobre as mudanças que a televisão operaria nossas vidas. Há 10 anos que não éramos capazes de imaginar como a Internet poderia mudar 
nossas relações interpessoais. Há apenas 3 anos eram impensáveis as novas formas de comunicação que têm surgido com a rapidíssima implantação dos celulares, ...

\section{O CONTEXTO MACROPSICOSSOCIAL E A INTERVENÇÃO SOCIAL}

Como psicólogos, é relevante termos em conta os elementos psicossociais do contexto, particularmente do ponto de vista macrossocial. Muitas vezes os psicólogos se definem como profissionais vinculados à esfera microssocial, como se as relações interpessoais não fossem também realidades existentes nos níveis macro. Neste sentido, é especialmente interessante o trabalho de S. Milgram, cada vez mais referenciado pelas disciplinas que estudam as redes sociais, intitulado The small world problem, que evidencia a importância macrossocial dos vínculos entre as pessoas.

No decorrer das práticas de intervenção e pesquisa, obviamente também estamos submersos nas representações sociais majoritárias de nosso contexto sócio-cultural e do momento histórico que vivemos. Quando, justificamos a necessidade de determinadas intervenções/políticas sociais, estamos apegados a essas lógicas majoritárias. É fundamental (e em alguns âmbitos eu me atreveria a dizer que, é urgente) que frente a qualquer situação ou dinâmica social sobre a qual se planeja uma necessidade de intervenção, aprofundamo-nos na análise das representações sociais que estão implicadas no contexto sócio-cultural.

Em ocasiões anteriores, propus que podemos analisar no mínimo três vertentes representativas da maioria dos fenômenos que são destinatários de políticas sociais (Casas, 1996, 1998):

a) As representações existentes a respeito do grupo ou dos grupos de pessoas afetadas;

b) As representações sobre o grau de implicação social que o fenômeno representa (Trata-se de um problema ou necessidade social?; Que grau de urgência ou prioridade tem seu confronto?); e,

c) As representações sobre as formas apropriadas de agir.

Quanto às representações existentes a respeito do grupo ou dos grupos de pessoas afetadas podemos afirmar que os programas de intervenção social, com exceção de alguns de prevenção primária, via de regra são pensados em função de, e dirigidos a, grupos ou coletivos concretos, sobre os quais existem imagens compartilhadas. Habitualmente, falamos de políticas setoriais. Cada grupo ou categoria de pessoas define um setor das políticas sociais como foco de intervenção. Por exemplo: os ciganos, os imigrantes, as crianças, as mulheres, os doentes mentais, os deficientes físicos, os sem teto, etc...

Ao longo da historia a configuração dos grupos muda, mas também, e talvez, sobretudo, muda nossa maneira coletiva de pensar a respeito de cada um desses grupos. Antes pensávamos em termos de pobres, agora nos socialmente excluídos; antes em termos de idiotas, imbecis, retardados mentais e anormais, agora de pessoas com necessidades especiais; antes pensávamos em termos de loucos e de perigo social, e agora em termos de doença mental e necessidade de apoio. Não quero dizer que esta mudança de conceitos de referência não seja simbolicamente muito importante. Mas é uma mudança de olhar que em si não garante uma ação adequada.

É preciso considerar as contribuições da psicologia social européia das últimas três décadas, ao pesquisar as relações intergrupais quando os humanos nos dicotomizam em grupos nos quais nós temos um forte sentimento de identidade (paios e ciganos; homens e mulheres; autótonos e imigrantes; adultos e crianças). Resumidamente, então aparecem:

- Tendências a enfatizar as semelhan-

ças intragrupais;

- Tendências a enfatizar as diferenças

intergrupais;

- Tendências a supervalorizar o endogrupo;

- Tendências a subvalorizar o exogrupo;

- Resistências a reconhecer as semelhan-

ças intergrupais e as diferenças intragrupais; e,

- Resistências a supercategorizar.

A luta contra muitas dinâmicas de exclusão social requer ter uma visão macrossocial das relações intergrupais, e uma capacidade de intervir para gerar dinâmicas opostas às assinaladas nos pontos referidos anteriormente, para prevenir e problematizar estereótipos e preconceitos - formas ativas de desvalorização e marginalização dos outros.

Recordemos que a definição de problema social proposta por muitos interacionistas simbólicos dá ênfase precisamente à percepção coletivamente compartilhada de uma realidade, mais que a própria realidade. Por exemplo, um fato social que um considerável número de pessoas julga desagradável ou desfavorável, e que, segundo eles, existe em sua sociedade. Um problema social carece de existência objetiva; ou melhor, se atribui caráter problemático a certos fatos ou condutas e associando a eles significado desfavorável. Segundo Vander Zanden (1977) pode-se até definir como problema social algo inexistente.

No que se refere ao grau de implicação social que o fenômeno representa podemos afirmar que o 
que tem justificado tradicionalmente a intervenção social, nas ciências humanas e sociais, tem sido o fato de que alguma coisa não anda bem na dinâmica social. A partir desta percepção mais o menos consensual, o único problema que restava era entrar em acordo quanto à denominação: marginalização social, problema social, necessidade social, inadaptação social, desvio, exclusão social, e um longo etc... Entretanto, nem todas as coisas que não andam bem são consideradas um problema ou necessidade social. Portanto, podemos inferir que é preciso restringir a intervenção social às situações legitimadas como problemáticas para cada sociedade, em cada momento histórico. A partir de então, implicam a lógica de que é preciso um suporte público para a atuação. Outras situações que afetam negativamente às pessoas seguirão sendo como problemas privados, ou pelo menos, sem implicações para os sentimentos de responsabilidade coletiva (Casas, 1996).

No século XX, a partir da década de 1960 , observa-se um movimento de mudança da lógica da intervenção sobre a base de conceitos conotados negativamente, para assumir que também podemos mudar coisas, por isso intervir socialmente, simplesmente para melhorar (sem que seja preciso concretizar o que vai mal, e delimitá-lo, quantificá-lo, atribuí-lo aos grupos ou categorias). Desse modo, institui-se num primeiro momento, a lógica da prevenção primária, e depois a lógica da promoção (da saúde, do bemestar, da qualidade de vida, da participação social, da potenciação da comunidade, p. ex.).

No que tange às representações sobre as formas apropriadas de agir, cabe ressaltar que ao mudar a lógica sobre onde é preciso intervir, também se favorece que se mude a lógica de como é preciso fazêlo.

Ao longo da historia da sociedade ocidental, desde a Idade Média, houve um único paradigma que sustentava o pensamento sobre o que é preciso fazer frente a problemas, ou necessidades sociais: Tomar conta da pessoa afetada, e levá-la a uma instituição especializada em seu problema ou necessidade. No início do século XX, a ciência não faz outra coisa que não seja avalizar essa lógica: o que é preciso fazer é definir bem os problemas, classificar adequadamente as pessoas portadoras, e desenvolver um programa de intervenção especializada, com pessoal especializado e em centros especializados naquele e só naquele problema. É o paradigma da especialização, que, paradoxalmente, depois de reinar durante séculos, em pouco mais de duas décadas é derrubado estrepitosamente, porque de todas as disciplinas científicas surgem questionamentos de raiz. Mesmo que não tenha já nenhuma sustentação teórica, sua inércia vai fazer com que na prática perdure de formas encobertas, ou melhor, descaradas. Não se pode ocultar que a mudança no novo paradigma, que denominarei paradigma da normalização, requer investimento econômico importante e, como decorrência, vontade política. Na prática, boa parte das administrações públicas têm resistido de forma prolongada à mudança paradigmática, ou, pelo menos, têm-nas atrasado. Aliás, algumas têm utilizado a bandeira da desinstitucionalização como objetivo de economia do gasto público, em vez de utilizá-la como ferramenta de mudança no processo de criação de novos serviços mais setorizados e perto do usuário. O novo paradigma já não se centra no problema, mas no contexto de atenção das pessoas que sofrem problemas ou necessidades. Representa uma ruptura aberta com as representações sociais sobre as quais se sustentava o paradigma anterior.

A finais do século XX, sem o novo paradigma estar implantado, aparece um terceiro, o dos direitos, que enfatiza o contexto no qual a pessoa ou usuário de um serviço mora, e se direciona aos seus interesses e pontos de vista. Como não existe pessoa sem contexto, este último paradigma não representa uma ruptura radical com a questão da normalização, mas só uma matizada mudança de perspectiva sobre a realidade.

O certo é que agora já não achamos adequado que se retire as pessoas de seu contexto habitual de vida por qualquer razão, e que fiquem em perigo os vínculos positivos estabelecidos entre pessoas. Em vez de mudar o lugar das pessoas, agora achamos mais apropriado mudar a tipologia e configuração dos serviços. Temos criado um amplo leque, com o propósito de dispor do mais normalizado possível para cada novo problema emergente.

\section{DEMANDA VERSUS POTENCIALIDADE: IDENTIDADE ATRIBUÍDA OU CONQUISTADA? \\ O contexto macropsicossocial no qual nós} trabalhamos, também contém estereótipos e representações sociais majoritárias sobre o psicólogo em geral e sobre os profissionais da intervenção social em particular. Uma idéia muito popular do que é um psicólogo e a do profissional que aplica testes e faz terapia. É preciso que nós nos perguntemos se temos feito e fazemos o suficiente para mudar este estereótipo e para que circulem outras idéias sobre nossas potencialidades. Se como conjunto de profissionais nós não somos pro-ativos, nossa tarefa ficará delimitada pela demanda. Então a identidade do psicólogo da intervenção será estritamente a que atribuam a ele aqueles que a contratarem.

Temos diversos exemplos sobre os quais refletir: Desde há mais de uma década praticamente em todas as universidades do estado espanhol a licencia- 
tura de psicologia inclui pelo menos uma matéria de Psicologia Comunitária; habitualmente também são oferecidos pós-graduações. Mas, que eu saiba, são bem poucas as administrações públicas que assinam contratos para trabalhar como psicólogo comunitário. Uma coisa é um enfoque que muitos psicólogos consideram apropriados por determinados processos de intervenção e outra é a identidade que os que nos contratam nos atribuem. Temos outro exemplo bem catalão nos EAIAs. O projeto inicial definia o psicólogo dessas equipes como de orientação social. A prática da contratação, os programas dos concursos e outros fatores têm feito com que a orientação social dependa da vontade de cada psicólogo; a identidade atribuída é diferente que a conquistada ou aspirada.

\section{AS DIMENSÕES NÃO-MATERIAIS NOS PROCESSOS DE MUDANÇA SOCIAL}

A história da psicologia, e, particularmente da psicologia social, está cheia de lutas com outras disciplinas para conseguir um reconhecimento da cientificidade do conhecimento produzido e das pesquisas efetivadas. Habitualmente ao longo da história temos sido acusados de estudar a realidade só com dados subjetivos e com indicadores subjetivos, e temse feito muita confusão com esse tema, geralmente em benefício de outros. É comum a dedução de que as próprias realidades que estudam não podem ser objetivas ou existir objetivamente. Academicamente e epistemologicamente esta disputa está superada.

Mas possivelmente nós, os psicólogos, não soubemos obter impacto suficiente dessa superação em benefício da profissão. Não soubemos explicar suficientemente bem que uma coisa é estudar uma realidade com técnicas subjetivas, e outra é que determinadas realidades existam objetivamente, por muito que sejam intangíveis, e que sua importância dentro dos processos de mudança social é fundamental. A insatisfação dos usuários de um serviço, a coesão social de um grupo ou comunidade, as atitudes, preconceitos, estereótipos, valores, ou aspirações coletivas existem, porém só podemos estudá-las com dados aproximados, que são os indicadores psicossociais de fenômenos sociais complexos, que geralmente exigem técnicas subjetivas para sua obtenção. E, além disso, sabemos perfeitamente que se um fenômeno é percebido como real, o será em suas conseqüências.

Um acontecimento que necessita de maior atenção coletiva por parte da psicologia é o aparecimento da investigação científica no campo da qualidade de vida nos finais dos anos 1960, e do desafio que esta aspiração representou na teoria, na pesquisa e nas políticas públicas. A qualidade de vida é um conceito que aparece entre os mais prototípicos dos denominados valores pós-materiais, ao longo dos anos
1960, no eixo dos interesses para estudar os processos sociais de mudança positiva. Hoje já esquecemos que a qualidade de vida é um âmbito de estudo científico, para identificá-lo como uma bandeira de muitas utilidades, que todos utilizam e manipulam com os propósitos mais heterogêneos, tal e como anos atrás se fez com o conceito de progresso.

A qualidade de vida, por definição, é um fenômeno que articula condições materiais de vida e condições psicossociais de vida, em relação a qualquer pessoa, ou grupo, comunidade ou sociedade humana.

Novos desafios que comportam o estudo da qualidade de vida e o trabalho profissional para sua promoção.

Uma definição tradicional das características do bem-estar social (Moix, 1980) destaca:

- Sua objetividade, ou seja, o fato de se referir a condições e circunstâncias objetivas de uma realidade social;

- O fato de ser uma realidade externa, ou seja, apreciável pelos outros; e, - O fato de partir de uns mínimos, ou seja, do nível que se considera indispensável para viver dignamente.

Quando se começa a assumir a qualidade de vida como um campo de estudo científico, por definição fica claramente consensuado (Casas 1996) que é uma função do ambiente material e do contexto psicossocial em que vivem as pessoas. Noutras palavras, ao estudo da qualidade de vida interessa tanto a objetividade, como a mal compreendida subjetividade das pessoas, definida como as percepções, avaliações e aspirações das pessoas em relação ao contexto social e sócio-cultural no que vivem (Campbell, Converse \& Rodgers, 1976).

A partir de então não se pode falar de qualidade de nenhum grupo humano ou população sem ter também em conta o ponto de vista de todos os agentes sociais implicados, incluídos os destinatários dos serviços. Assim como não se poderá falar de qualidade de um serviço sem ter em conta as avaliações dos usuários.

Isto faz estremecer algumas maneiras de compreender a função social do profissional como especialista. Logicamente, uma coisa que pode acontecer, e acontece, é que as avaliações da realidade (e das urgências o prioridades para encará-la) dos especialistas e dos cidadãos são discrepantes. Na historia dos estudos sobre qualidade de vida esta questão é bem conhecida, porque deu lugar a uma década inteira de debates estéreis. Quem tem (mais) razão? Quem sabe mais sobre diabetes, o diabético ou o médico especialista em diabetes? A tentação é responder que, "naturalmente 'nós', os especialistas, sempre sabemos mais 
que os usuários dos serviços. Cabe ressaltar que, entre os especialistas, os que devem ter mais razão são aqueles que trabalham com dados mais 'objetivos' e não os que estudam os 'subjetivos' (como, p. ex., as opiniões das pessoas, sua satisfação com os serviços, seu bem-estar psicológico, ou sua satisfação com a vida) (Casas, 1996).

Nos campos de estudos da qualidade de vida esse debate é considerado superado, embora siga havendo especialistas que ignoram a população ou os destinatários de seus serviços (o âmbito da infância é um claro exemplo - Casas, 1998). Atualmente se considera que a pergunta cientificamente produtiva é: Porquê discordam? Porquê diferentes agentes sociais têm perspectivas bem diferentes de uma mesma realidade? Como encarar a realidade problemática, em meio às diferentes percepções da mesma? Como gerar dinâmicas de consenso no processos de confronto e mudança do problema ou necessidade social?

Recordemos alguns exemplos de situações que se podem acontecer e que podemos considerar lições a aprender acerca dos velhos debates sobre a qualidade de vida:

- Se os especialistas em geriatria dizem que num município o mais urgente são mais vagas de residências assistidas e as pessoas mais velhas do município reivindicam mais bochas, quem tem razão?; - Se os especialistas de um complexo sanitário argumentam um aumento da qualidade dos serviços, observáveis pela diminuição do número de disfunções, enquanto os usuários argumentam uma diminuição desta qualidade pela desinformação e falta de bom trato por parte dos peritos, quem tem razão?; e, - Se os adultos consideram que é preciso limitar as atividades de risco dos adolescentes pela sua excessiva acidentalidade, e os adolescentes preferem ignorar as recomendações adultas por seu excessivo afã de controle, quem vai levar a razão?

Quando nós, especialistas e cidadãos, temos a mesma perspectiva (a mesma representação social compartilhada) de uma realidade concreta, não há nenhum debate: Todos estamos de acordo que isso é assim, e só é preciso atribuir-lhe um nome (p. ex.: marginalização, injustiça social, inadaptação, desvio, problema, necessidade, etc., se a denominação está conotada negativamente; bem-estar, satisfação, felicidade, progresso, etc. Mas se nossas perspectivas são discrepantes, então aparece uma realidade diferente, sobre a que haveremos de discutir. As pessoas mais velhas do povo de alta montanha que não querem habitar uma residência destinada a elas, embora sua casa esteja sendo derrubada, mas que querem seguir com seus vizinhos, o que são? Como os classificamos? Adaptados a condições adversas de vida? Conformistas?

Os estudos sobre qualidade de vida, querendo integrar as percepções, avaliações e aspirações dos sujeitos (condições psicossociais de vida), com as condições materiais e observáveis de vida, forçam uma revolução conceitual, mas também obrigam a uma revisão profunda da pesquisa científica psicossocial, e da intervenção social e psicossocial. Em efeito, no mundo da pesquisa científica muito cedo se começam a pesquisar novos fenômenos que não são os meros antônimos do que estudávamos até então, quando enxergávamos o que vai mal. A curiosidade de estudar a realidade social e psicossocial abre novas portas e janelas, e começam, aliás, a investigar temas até então tão estranhos para a ciência,. Nesta perspectiva encontra-se a questão da felicidade, considerada terreno para filósofos, porque cada um é feliz como quer, e isto não parecia objeto de pesquisa científica. Outros temas pelos que nasce um grande interesse dos investigadores são:

- Bem-estar psicológico (o subjetivo);

- Satisfação vital;

- Satisfação com âmbitos da vida (família, trabalho, vizinhança, amizade,

lazer, saúde, etc...);

- Concorrência condutual;

- Qualidade de vida percebida; e,

- Optimismo vital. E um longo etc.

\section{A PREVENÇÃO EM POSITIVO}

Uma visão em positivo sobre a realidade faz que nós, pesquisadores e profissionais, enxerguemos a prevenção não só como um trabalho contra os fatores de risco, mas, também como um trabalho a favor dos fatores de proteção ou resiliência. Aparentemente essa nova perspectiva tem sido assumida rapidamente pelos profissionais da intervenção social em geral.

Uns dados de um estudo recente com uma mostra ampla de profissionais dos serviços sociais à infância da Comunidade de Madrid nos convidam, porém, a seguir refletindo. Trata-se de profissionais com, em média, mais de oito anos de experiência no âmbito. Segue uma síntese das conclusões do estudo (Casas, González, Calafat, \& Fornells, 2000):

- Observa-se uma grande heterogeneidade de critérios entre os profissionais no momento de definir tanto fatores de risco, como fatores de proteção social, que se considerem relevantes para orientar a tomada de decisões e a intervenção social com crianças e suas famí- 
lias;

- Os profissionais mostram uma grande capacidade por analisar detalhadamente os fatores de risco microssociais, mas não se observa um nível equivalente em analisar os fatores de proteção, nem os fatores macrossociais de risco ou de proteção;

- Os profissionais utilizam diferentes teorias implícitas ou modelos organizadores em seu processo de identificar e decidir sobre a relevância de fatores de risco e de proteção, que não parecem corresponder aos paradigmas psicológicos tradicionais (psicanálise, conductismo, cognitivismo, sistemática, etc.), mas que parecem próprios de cada equipe, já que os membros de um mesmo equipe parecem tender a dar justificativas parecidas suas escolhas; e,

- Todo isto parece sugerir a existência de um déficit de debate entre profissionais, para contrapor experiências e aproximar posições conceituais como de prática profissional.

A difícil relação dos profissionais da intervenção social com os médios de comunicação social.

As políticas sociais não estão na moda nessa dinâmica planetária de globalização em que estamos submersos. Também não está na moda falar de problemas sociais na televisão, se as imagens que se podem oferecer não são capazes de impactar uma audiência.

Neste contexto, nós, os profissionais da intervenção social, temos nos ressentido pelo tratamento das informações sobre as situações que sofrem nossos usuários) por parte dos meios de comunicação social. Enxergamos e nos relacionamos com seus profissionais com desconfiança e, às vezes, aliás, como uma espécie de inimigo a evitar.

Em nossa sociedade em transformação acelerada é difícil imaginar mudanças notáveis nas atitudes gerais dos cidadãos, ou em suas representações sociais respeito a questões que afetam os programas de intervenção social, sem contar com a colaboração positiva dos meios de comunicação. Mais de um psicólogo comunitário tem procurado conseguir uma atitude positiva numa comunidade determinada sobre, por exemplo, o acolhimento familiar de crianças em família aliena, e tem visto com desesperação como a tarefa de dois meses tem sido destruída por uma telenovela, o realizador da qual não tinha compreendido nada desta modalidade de acolhimento. Mas, acontece que, o imaginário de uma parte da audiência tem percebido que um seriado de TV tem mais elementos concretos de realidade que não o discurso de um profissional.

Será preciso, então, repensar nossas colaborações e alianças com os profissionais da informação e, particularmente, será preciso repensar nossas redes para dinamizar mudanças sociais positivas.

Um esquema resume para continuar a reflexão sobre os desafios da intervenção social

Mais que dispor de alguma resposta clara, minha contribuição tem pretendido sugerir uma relação de aspectos a repensar que, são chaves para a necessária redefinição da tarefa profissional do psicólogo como interventor social de frente para o futuro próximo. Obviamente, esta relação fica aberta. Estruturei as perguntas nucleares em cinco:

- Mudar o que?;

- Mudar para qual direção ?;

- Mudar como?;

- Mudanças em que contexto?; e,

- Mudar no âmbito microssocial o macrossocial?

O contexto compreendo que é, sem dúvida, o de uma sociedade em transformação acelerada, e o nível de atuação é o micro e o macro no mesmo momento, pelo que será preciso analisar como ter mais em consideração os elementos psicossociais dos níveis macrossocial, para poder incidir neles. A partir de aqui, eu tenho ordenado minha proposta de reflexão-trabalho no seguinte resumo esquemático de alguns desafios 'quentes' da psicologia da intervenção social.

\section{MUDAR O QUE?}

a) Sobre a base de uma Psicologia da categorização/ construção psicossocial das realidades sociais:

- Gênese e legitimação dos problemas e

das necessidades sociais;

- Gênesis e legitimação das aspirações

sociais;

- (progresso, bem-estar, qualidade de vida);

- Representações sociais amplamente compartilhadas sobre grupos/categorias de pessoas;

- (informações, atitudes, núcleo figurativo).

b) Sobre a base de uma Psicologia da ação social e as políticas sociais:

- O que é social?

o Assumir de responsabilidades coleti-

vas; e,

o Implicação das instancias públicas.

- A lógica de intervir para mudar reali-

dades negativas versus a lógica de pro-

mover realidades positivas (psicologia 
positiva); e,

- O que é preciso mudar: pessoas, situações, processos ou dinâmicas ou interações sociais?

Representações sociais amplamente compartilhadas de o que são problemas ou necessidades sociais.

\section{MUDAR PARA QUAL DIREÇÃO?}

c) Sobre a base de uma Psicologia da antecipação e a planificação:

- Projetar o presente versus o futuro. o O que acontece se nós não agirmos? (informar e convencer que é preciso agir); e, o O que pode acontecer se nós agirmos? (dispor conhecimentos e influência).

- Capacidade de antecipar (limites do contexto social).

o Imaginar situações alternativas possíveis (novas, utópicas?).

- Definir objetivos.

o (temos ideais, modelos ou padrões de comparação?); e, o (conhecimento teórico e/ou experimentado).

- Processos de mudança ancorados em valores e aspirações.

o (p.ex.: educar na responsabilidade). - Os desafios da qualidade de vida.

\section{MUDAR COMO?}

d) Sobre a base de uma Psicosociologia dos métodos e técnicas de intervenção social:

- As lógicas da intervenção social.

o Representações sociais majoritárias das formas apropriadas de desenvolver intervenções sociais;

- Paradigma da especialização: Focalizado na identificação do problema e sua categorização;

- Paradigma da normalização: Focalizado no contexto organizativo para poder afrontar o problema adequadamente; e,

- Paradigma dos direitos: Focalizado na perspectiva do cidadão ou usuário/ usuária de serviços e de seus direitos. o Nós, psicólogos e pesquisadores da intervenção social, também estamos imersos nessas representações sociais majoritárias.

- Os mecanismos de influencia social

o Exercer poder especialista;

o Dinamizar (participação, advocacia, potenciação, promoção); e, o Mediar (ajudar que a mudança seja decidida pelos implicados).

- A cultura de avaliação (funções sociais da avaliação).

- As interações com outros agentes sociais:

o Multi/pluri/inter profissionalidade/ disciplinariedade;

o Trabalho em rede;

o Pesquisa-ação; e,

o O poder dos MCS e das NTICs.

- Trabalhar as discrepâncias perceptivas dos diferentes agentes sociais e as próprias discrepâncias perceptivas, avaliativas e representacionais entre os próprios profissionais (interventores e pesquisadores);

- Identidade profissional: atribuída ou conquistada?;

- Paradoxo da falta de currículo específico na formação acadêmica, versus implantação profissional;

- Demanda ou proatividade?;

- Coalizões e alianças: Com ou contra os MCS, as NTICs?;

- A função de promover o bem-estar e a qualidade de vida; e,

- As funções dos psicólogos dos serviços sociais:

o Formador, planificador, gestor, avaliador;

o Por âmbitos; e,

o Segundo perspectivas: comunitária, de redes.

Nesta conjuntura, eu compreendo que resulta transcendente abrir novos debates sobre:

- Intervir para melhorar, com o objetivo da qualidade de vida;

- Importância das dimensões não-materiais das dinâmicas sociais nos processos de mudança;

- Representações sociais;

- Relações intergrupais e intergeracionais;

- Prioridade e mudanças nos sistemas de crenças e valores;

- Aspirações coletivas: Os objetivos como orientadores da ação. A qualidade de vida.

- As atuações sociais de alto consenso e baixa intensidade (p. ex.: os direitos das crianças. Todos estão de acordo, mas poucas vezes se considera prioritário); e, 
- O uso de MCS e de NTICs.

Em síntese, eu considero que é preciso repensar a intervenção social e psicosocial nas seguintes coordenadas:

- Numa sociedade em transformação acelerada;

- Em positivo;

- Considerando os contextos macrossociais, sem abandonar os micro (nós temos muito trabalho por fazer ainda nos macro);

- Desenvolvendo dinâmicas profissionais proativas: cultura de avaliação, autoformação por contraste de experiências, dinamizar redes;

- Trabalhando em novas redes e alianças; e,

- Fazendo marketing da importância das dimensões não-materiais das dinâmicas sociais nos processos de mudança positiva.

\section{REFERÊNCIAS}

Campbell, A., Converse, P. E., \& Rodgers, W. L. (1976). The quality of American life: pPerceptions, evaluations and satisfactions. New York. Russell Sage.

Casas, F. (1996). Bienestar social: una introducción psicosociológica. Barcelona: PPU.

Casas, F. (1998). Infancia: perspectivas psicosociales. Barcelona: Paidós.

Casas, F., González, M., Calafat, C., \& Fornells, M. (2000). Riesgo y protección en la población infantil: factores sociales influyentes según los profesionales de la comunidad de Madrid. Madrid: Cuadernos Técnicos de Servicios Sociales / Consejería de Servicios Sociales.

Moix, M. (1980). El bienestar social: ¿Mito o realidad?. Madrid. Almena.

Vander Zanden, J. W. (1977). Social psychology. New Cork: Random House.
Ferrán Casas é PhD. em Psicologia. Professor do Departamento de Psicologia e Diretor do Instituto de Investigação sobre Qualidade de Vida (IRQV) na Universidade de Girona, Espanha. Endereço para correspondencia: Pl. S. Domènec, 9, CEP 17071, Girona (Espanha). Fax + 34972418345.

E-mail: ferran.casas@udg.es

\section{Ferrán Casas \\ Desafios atuais da psicologia \\ da intervenção social \\ Recebido: 02/09/2005 \\ Aceite final: 14/10/2005}

